\title{
Martin Vahlensieck, Maximilian Reiser: MRI of the musculoskeletal system
}

\author{
Thieme, Stuttgart, New York, Delhi, Rio de Janeiro, 2018, 677 p., format $23.5 \times 31.5 \mathrm{~cm}, 2062$ \\ illustrations, ISBN 978-3-13-1165725, elSBN 978-3-13-1607928
}

\section{Bruno Grignon ${ }^{1}$}

Received: 17 January 2018 / Accepted: 18 January 2018 / Published online: 9 February 2018

(c) Springer-Verlag France SAS, part of Springer Nature 2018

This book is the second English edition of an exhaustive review of the most important principles and clinical applications of musculoskeletal magnetic resonance (MR) imaging, including the latest advanced techniques.

The editors are Martin Vahlensieck, Professor of Radiology in Bonn, Germany, and Maximilian Reiser, Professor of Radiology in Munich, Germany. An international panel of 22 German, Austrian, Swiss and American contributors has collaborated in writing this work.

It is divided into 16 chapters, in sequential order devoted to: magnetic resonance imaging technique, the spine, the shoulder, the elbow, the wrist and fingers, the hip and pelvis, the knee, lower leg, ankle and foot, the temporomandibular joint, the muscles, bone marrow, bone and soft tumor, osteoporosis, the sacroiliac joints, the jaws and periodontal apparatus, and miscellaneous minor topics sorted in an appendix.

Each chapter includes: choice of sequences, selection of coils, patient positioning, technical parameters and protocols, when/how to use contrast, anatomical and clinical reminders, pathological findings, pitfalls in interpreting the images, comparison of MRI with other imaging modalities, by means of a concise and comprehensive text, numerous pedagogical drawings, tables, some photographs and anatomical specimens, and, most of all, more than 2,000 MR images, all of high quality and large size.

A precise plan including the page number of the corresponding paragraphs is displayed at the beginning of each chapter, in addition to the main table of contents and the subject index, allowing a practical and quick use of the book. In addition to updated references displayed at the end of each chapter, internet sites have been referred to by the authors, and research tips on more effective use of internet search terms are also given. A short section, entitled "Clinical Interview", concludes each chapter with the opinions of a renowned clinical radiologist regarding some debatable issues in the field.

Designed to accompany the radiologist at the workstation on a daily basis, this updated, complete, and wonderfully illustrated work may be of great value for all physicians responsible for the care of musculoskeletal disorders.
Bruno Grignon

b.grignon@chu-nancy.fr

1 University of Lorraine, CHU Nancy, Nancy, France 